\title{
Article
}

\section{Preclinical studies of granulysin-based anti-Tn immunotoxins as a new antitumoral treatment}

\author{
Patricia Guerrero-Ochoa ${ }^{1}$, Raquel Ibáñez-Pérez ${ }^{1}$, Germán Berbegal-Pinilla ${ }^{1}$, Diederich Aguilar ${ }^{2}$, Isabel Marzo ${ }^{1}$, \\ Francisco Corzana ${ }^{3}$, Blanca Conde ${ }^{1}$, Javier Raso ${ }^{2}$, Ramón Hurtado-Guerrero ${ }^{4,5,6,7}$ \& Alberto Anel ${ }^{1 * *}$ \\ ${ }^{1}$ Apoptosis, Immunity and Cancer Group, Aragón Health Research Institute (IIS-Aragón), University of Za- \\ ragoza, 50009 Zaragoza, Spain; docenteashlaboratorio@gmail.com (P.G.-O.); raquelip@unizar.es (R.I.-P.), \\ germanberbegalpinilla@gmail.com (G.B.P.), imarzo@unizar.es (I.M.), bconde@unizar.es (B.C.), \\ anel@unizar.es (A.A.) \\ ${ }^{2}$ Food Technology, Facultad de Veterinaria, Instituto Agroalimentario de Aragón-IA2, Universidad de Zara- \\ goza-CITA, 50013 Zaragoza, Spain; diederichaguilarmac@uadec.edu.mx (D.A.-M.); jraso@unizar.es (J.R.) \\ ${ }^{3}$ Department of Chemistry. Research Center for Chemical Synthesis. University of La Rioja. 26006. Logroño, \\ Spain. francisco.corzana@unirioja.es (F.C.) \\ ${ }^{4}$ Biocomputation and Physics of Complex Systems Institute (BIFI), University of Zaragoza, 50018 Zaragoza, \\ Spain; rhurtado@bifi.es (R.H.-G.) \\ ${ }^{5}$ ARAID Foundation, 50018 Zaragoza, Spain \\ ${ }^{6}$ Department of Cellular and Molecular Medicine, Copenhagen Center for Glycomics, University of Copen- \\ hagen, 2200 Copenhagen, Denmark \\ ${ }^{7}$ Laboratorio de Microscopías Avanzada (LMA), University of Zaragoza, 50018 Zaragoza, Spain \\ *Correspondence: anel@unizar.es; Tel.: +34-976-761279; Fax: +34-976-762123
}

\begin{abstract}
Two granulysin (GRNLY) based immunotoxins were generated, one containing the scFv of the SM3 mAb (SM3GRNLY) and the other the scFv of the AR20.5 mAb (AR20.5GRNLY). These $\mathrm{mAb}$ recognize different amino acid sequences of aberrantly O-glycosilated MUC1, also known as the Tn antigen, expressed in a variety of tumor cell types. We first demonstrated the affinity of these immunotoxins for their antigen using surface plasmon resonance for the purified antigen and flow cytometry for the antigen expressed on the surface of living tumor cells. The induction of cell death of tumor cell lines of different origin positive for Tn antigen expression was stronger in the cases of the immunotoxins than that induced by GRNLY alone. The mechanism of cell death induced by the immunotoxins was studied, showing that the apoptotic component demonstrated previously for GRNLY was also present, but that cell death induced by the immunotoxins included also necroptotic and necrotic components. Finally, we demonstrated the in vivo tumor targeting by the immunotoxins after systemic injection using a xenograft model of the human pancreatic adenocarcinoma CAPAN-2 in athymic mice. While GRNLY alone did not have a therapeutic effect, SM3GRNLY and AR20.5GRNLY reduced tumor volume by 42 and $60 \%$, respectively, compared with untreated tumor-bearing mice, although the results were not statistically significant in the case of AR20.5GRNLY. Histological studies of tumors obtained from treated mice demonstrated reduced cellularity, nuclear morphology compatible with apoptosis induction and active caspase-3 detection by immunohistochemistry. Overall, our results exemplify that these immunotoxins are potential drugs to treat Tn-expressing cancers.
\end{abstract}

Keywords: immunotoxins; granulysin; Tn antigen; MUC1

Key Contribution: The immunotoxins developed were able to increase the antitumor capacity of granulysin and demonstrated in vivo targeting towards $\mathrm{Tn}^{+}$tumors. 


\section{Introduction}

The Tn antigen is mostly known as an aberrant hypoglycosylation of the MUC-1 membrane protein. This consists in an N-acetylgalactosamine (GalNAc) O-linked glycosylation and occurs at serine (Ser) or threonine (Thr) residues of glycoproteins [1]. Following the formation of the Tn antigen, the GalNAc residue can be further modified by distinct glycosyltransferases and construct different glycan structures. MUC-1 was the first transmembrane mucin to be identified and structurally characterized [2]. The aberrantly O-glycosilation of MUC 1 occurs in most epithelial cancers [3], and has been classified by the National Cancer Institute as one of the most promising tumor antigens to be targeted by new treatments [4].

It has been clearly demonstrated that the expression mechanisms of the Tn antigen result from genetic changes that lead to decreased expression of Cosmc and / or T synthase [5]. However, there are other possible factors that could influence the glycosylation and expression pathways of the Tn antigen, such as UDP-Gal or its transporter [2].

In the mid-1990s, 56 anti-MUC1 monoclonal antibodies were compared and their epitopes mapped. Among others, the anti-Tn antigen SM3 and AR20.5 mAb were evaluated [6]. They recognize a six amino acid sequence of MUC1 [7, 8]. In normal cells, the heavy O-glycosylation of the VNTR sequence of 20-21 amino acids masks the peptide core and protects it from cleavage by proteolytic enzymes, and also prevents it from undergoing clathrin-mediated endocytosis [1]. MUC1 and some growth factors are confined to the apical and basolateral surface of normal epithelium. The aberrant hypoglycosylation of MUC1 correlates with the loss of apicobasal polarity, so that it is localized throughout the cell surface [1].

Early reports showed the antitumor capacity of SM3 in different experimental settings $[9,10]$ and, afterwards, it has been used to generate effective anti-tumor CAR T cells $[11,12]$. The initial non-humanized version of AR20.5 was used in a clinical assay upon the commercial name of Brevarex®, but the xenogenic response mostly blocked the effects of the treatment [13]. A recent preclinical study using a humanized version of AR20.5 in combination with poly:ICLC and with anti-PD-L1 mAb gave excellent results against pancreatic tumors [14].

On the other hand, our research group has studied the antitumor capacity of recombinant $9 \mathrm{kDa}$ granulysin (GRNLY) for more than two decades [15-18]. Previous studies showed the in vivo tumor targeting of MFE23GRNLY, an immunotoxin engineered against the carcinoembryonic antigen (CEA), after systemic injection [19]. This therapy would be directed to tumors with high expression of CEA, mostly colorectal or gastric tumors [20]. Since the expression of the Tn antigen is observed in a much wider variety of tumor types, targeting this antigen would expand the possible therapeutic applications of granulysin-based immunotoxins. In order to optimize the antitumor capacity of Tn antigen-targeted therapies, we have designed two immunotoxins combining SM3 and AR20.5 with GRNLY.

The standard protocol to obtain recombinant proteins on P. pastoris (Komagataella phaffii), previously used by our group to produce MFE23GRNLY [19], did not allow to obtain enough of the new anti-Tn immunotoxins to face in vivo experiments. For this reason, various steps of the production and purification process were modified in search of an optimized protocol. In addition, we used a non-thermic technology, yeast electroporation by pulsed electric fields (PEF), to obtain the intracellular protein and increase the yield of production [21].

\section{Results}

2.1. Design of Recombinant Immunotoxin and Yield of Production 
The construct coding for the $9 \mathrm{kDa}$ granulysin (GRNLY) gene alone was described in our previous works $[19,21]$. We designed constructs to encode for the two anti-Tn immunotoxins formed by granulysin bound through a flexible linker of 23 amino acids (formed by Ser and Gly residues) to the anti-Tn scFv SM3 or AR20.5, respectively. A 17 amino acid linker was also introduced between the VL and VH sections of the scFv (Figure 1). All constructs included a tag of six histidines to facilitate detection and purification. Plasmids were amplificated in Escherichia coli and isolated. Isolated plasmids were then linearized with SacI and purified. Finally, plasmids were transfected by electroporation in Pichia pastoris and the transfected colonies selected, as indicated in Materials and Methods.

As indicated in our previous work [21], the yield of production of recombinant GRNLY was good, around $5 \mathrm{mg} / \mathrm{L}$ in the different batches, but the yield of production of SM3GRNLY was lower, around $2 \mathrm{mg} / \mathrm{L}$. Taking into account the difference in molecular weight, this difference in weight yield meant a difference of 10 -fold in molar yield. This low yield precluded the development of in vivo experimentation with the immunotoxin, our final objective. We then performed extraction of intracellular SM3GRNLY (iSM3GRNLY) using the PEF technique, and obtained more than $8 \mathrm{mg}$ per liter of yeast medium, four-fold the protein that was secreted to the supernatant. Regarding AR20.5GRNLY, the situation was even more unfavorable, being the yield of the extracellular protein as low as $0.5 \mathrm{mg} / \mathrm{L}$. When applying the PEF technology to obtain the intracellular protein, the yield increases as much as to $12.9 \mathrm{mg} / \mathrm{L}$. All these data are depicted in Table I. However, these iAR20.5GRNLY preparations contained another protein impurity that was not possible to eliminate in the purification process (data not shown). As a consequence, we could only work with the low amounts of extracellular AR20.5GRNLY obtained in the different batches.

\subsection{Immunotoxin affinity for its antigen in vitro.}

Using Surface Plasmon Resonance, the affinity of the MUC21T peptide for SM3GRNLY was determined by immobilizing 5700 resonance units (RUs) of the immunotoxin on a CM5 sensor chip, using the standard amine protocol. The response measurements were performed with increasing antigen concentrations from $0.5 \mu \mathrm{M}$ to $500 \mu \mathrm{M}$ (Figure 1A and 1B). The KD obtained using this method was of $2.79 \mu \mathrm{M}$. Regarding the affinity of SM3GRNLY for its antigen, 390 RUs of MUC21T were immobilized and increasing concentrations of SM3GRNLY from $2.5 \mathrm{nM}$ to $1 \mu \mathrm{M}$ were tested. The $\mathrm{K}_{\mathrm{D}} \mathrm{ob}-$ tained was of $0.149 \mu \mathrm{M}$ (Figure 1C and 1D). The kinetic adjustment of these last measurements established a KD of $0.122 \mu \mathrm{M}$ (Figure 1E).

To establish the affinity of MUC21T for AR20.5GRNLY, 6800 RUs of the immunotoxin were immobilized in the biosensor and the response was measured with increasing concentrations of the antigen from $0.07 \mu \mathrm{M}$ to $1 \mu \mathrm{M}$, obtaining a KD of $16.4 \mu \mathrm{M}$ (Figure $2 \mathrm{~A}$ and 2B). Regarding the affinity of AR20.5GRNLY for its antigen, a similar assay as that indicated above for SM3GRNLY was performed. However, the low concentrations of AR20.5GRNLY did not allow performing a reliable $K_{D}$ calculation. The sensogram data were double referenced using the Biaevaluation X-100 software and the experimental data from the affinity measurements were fitted to a site-specific binding pattern using Prism software. The result obtained for this kinetic adjustment was a $K_{D}$ of $0.206 \mu \mathrm{M}$ (Figure 2, lower panel). 


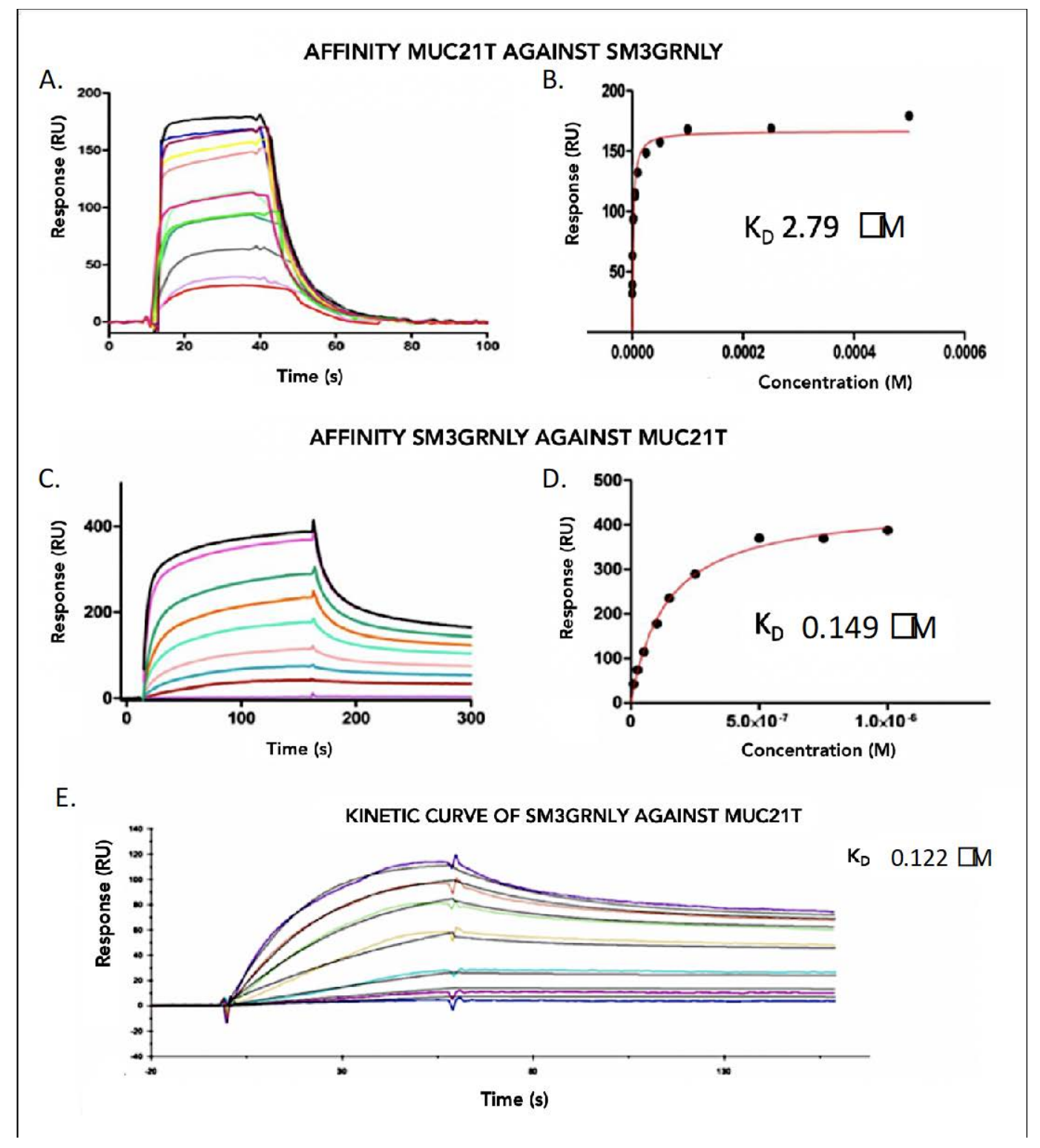

Figure 1. SM3GRNLY-MUC1-Tn SPR Affinity Assays. A-B: 5700 RUs of SM3GR were immobilized on the biosensor. The response was measured at different concentrations of the antigen, ranging from $0.05 \mu \mathrm{M}$ to $500 \mu \mathrm{M}$. C-D: 390 RUs of MUC1-Tn were immobilized and different concentrations of SM3GRNLY were studied. E: KD calculation using kinetic adjustment.

The reported $K_{D}$ for the AR20.5 antibody on Tn was $0.43 \mu \mathrm{M}$ [8], while for the SM3 antibody it was $0.45 \mu \mathrm{M}$ [3]. Hence, the affinity of GRNLY-linked immunotoxins for their antigen is in the range of those previously observed for the antibodies themselves. These results demonstrate that the antibody moiety of the immunotoxins conserved their high affinity for the purified Tn antigen.

\subsection{Immunotoxin recognition of its antigen on the cell surface}

In our previous study, and using flow cytometry, we demonstrated that both SM3GRNLY and iSM3GRNLY recognized Tn expression on the surface of living tumor cells previously reported to be positive for the expression of this antigen, including the pancreatic adenocarcinomas Panc-1 and CAPAN-2, the multiple myeloma NCI-H929 an the acute lymphocytic leukemia Jurkat [21]. 
We have now tested the binding of AR20.5GRNLY to these cell lines and results are depicted in Fig 3. The labeling was much more intense than that observed previously for SM3GRNLY, positive in the same cell lines indicated above, but also positive in the case of the lung adenocarcinoma A549 and the mammary carcinoma MCF7, whose labeling

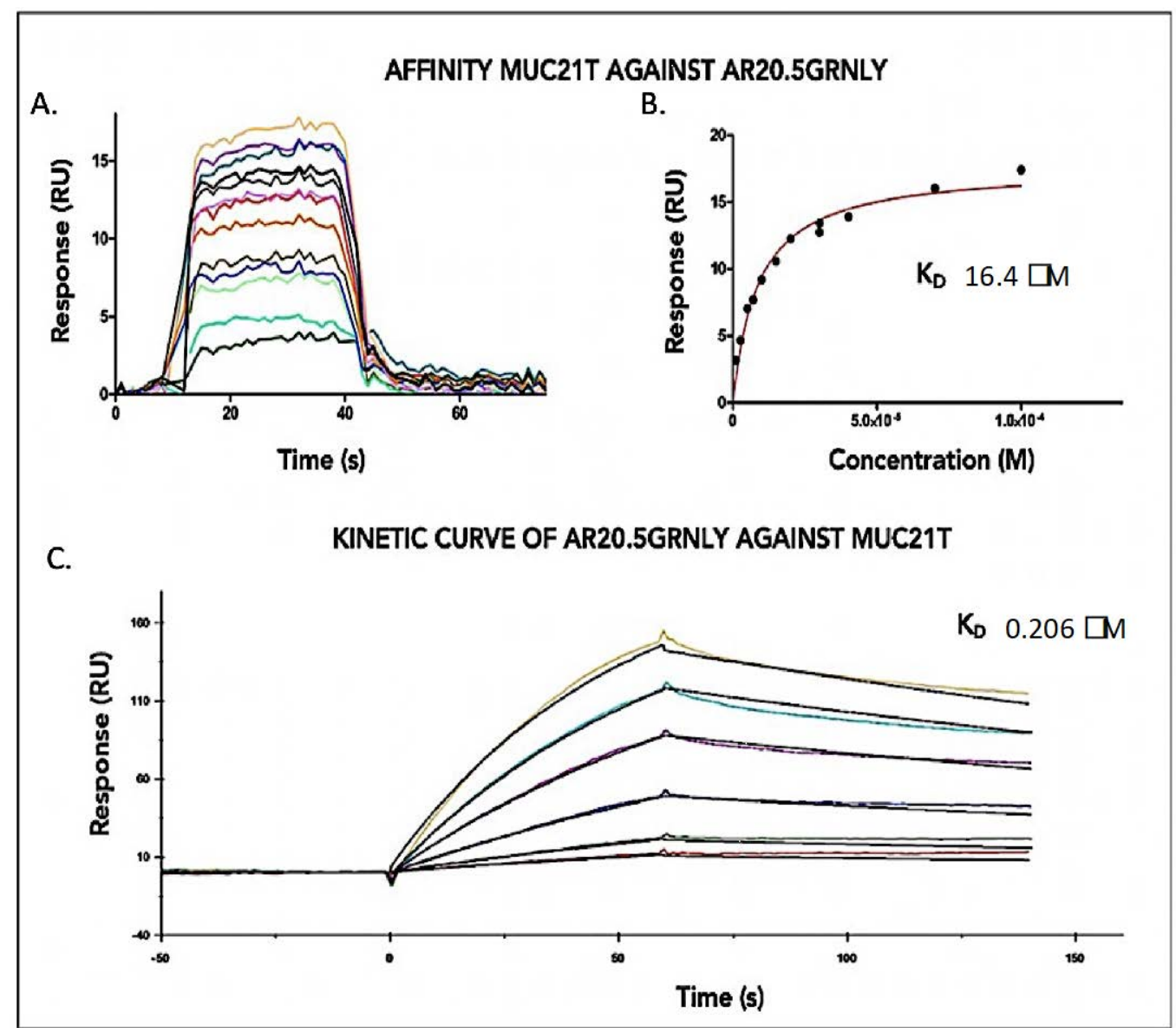

Figure 2.AR20.5GR-MUC1-Tn SPR Affinity Assays. A-B: 6800 RUs of AR20.5GR were immobilized on the biosensor, the response was measured with different concentrations of the antigen, varying from $0.07 \mu \mathrm{M}$ to $1 \mu \mathrm{M}$. C: Kinetic curve of AR20.5GRNLY when the target was immobilized.

with SM3GRNLY was very low [21]. As shown in the relative MFI ratios depicted in Supplementary tables 1 and 2, while the maximum ratio obtained with SM3GRNLY was 6.51 in Jurkat cells, this ratio was 13.32 on the same cell line when using AR20.5GRNLY. The higher increase in labeling, more than four-fold, was observed in the case of the pancreatic adenocarcinoma CAPAN-2. All these labeling were specific, since the Tn-negative cell line MDA-MB-231 [22] was negative for labeling with SM3GRNLY, iSM3GRNLY [21] or AR20.5GRNLY, a property shared by the pancreatic adenocarcinoma MiaPaca2 (Fig 3) [23] 


\section{AR20.5GRNLY}

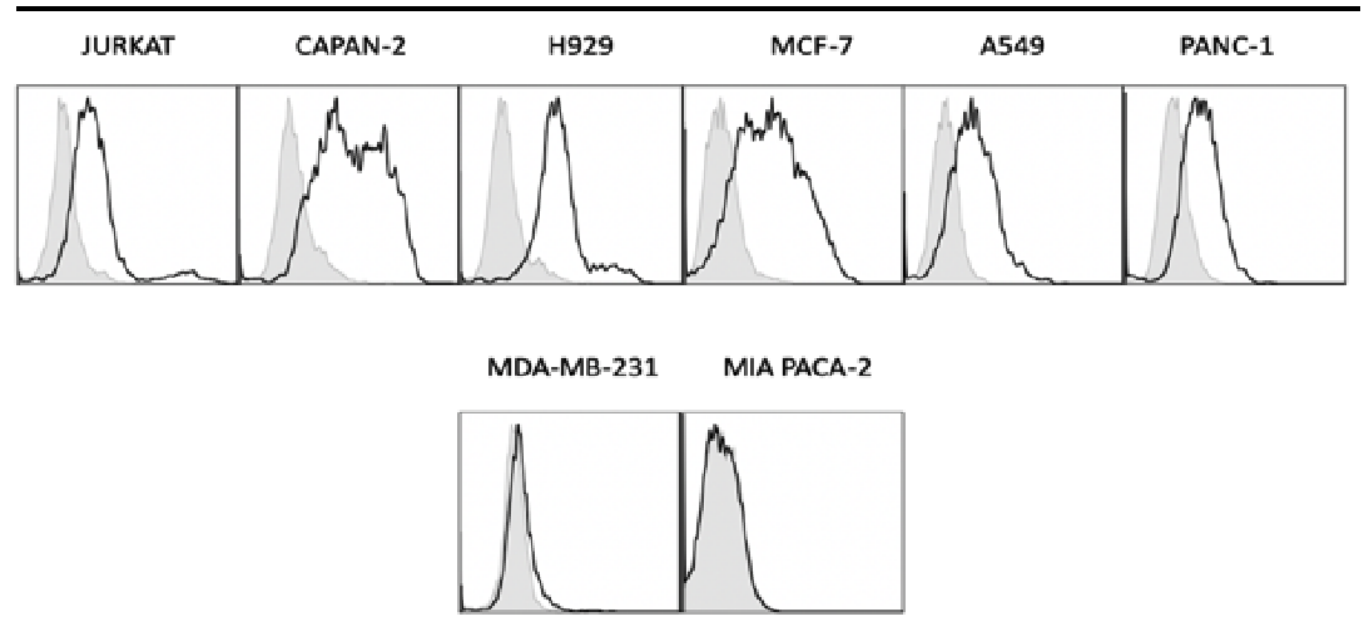

Figure 3. Recognition of the Tn antigen on the cell membrane of tumor cell lines. Shaded histograms correspond to cells incubated with PBS as negative control and open histograms correspond to cells incubated with AR20.5GRNLY, anti-His-tag antibody and FITC-conjugated goat anti-mouse IgG antibody.

\subsection{Cytotoxicity assays on $\mathrm{Tn}^{+}$tumor cells}

Once the recognition capacity of its antigen was established, the induction of cytotoxicity by immunotoxins was evaluated in comparison with GRNLY. The cytotoxicity of SM3GRNLY and iSM3GRLY was tested in our previous study on MCF7, A549, Capan-2, Panc-1 and H929 cells, correlating with their low (MCF7, A549) or high (Capan-2, Panc-1 and H929) surface binding to the Tn antigen [21]. In the present work we have analyzed their cytotoxicity on Jurkat cells, a cell line with reported high Tn expression due to Cosmc mutation [24, 25] and with a high binding rate of the immunotoxins [21].

\section{JURKAT}

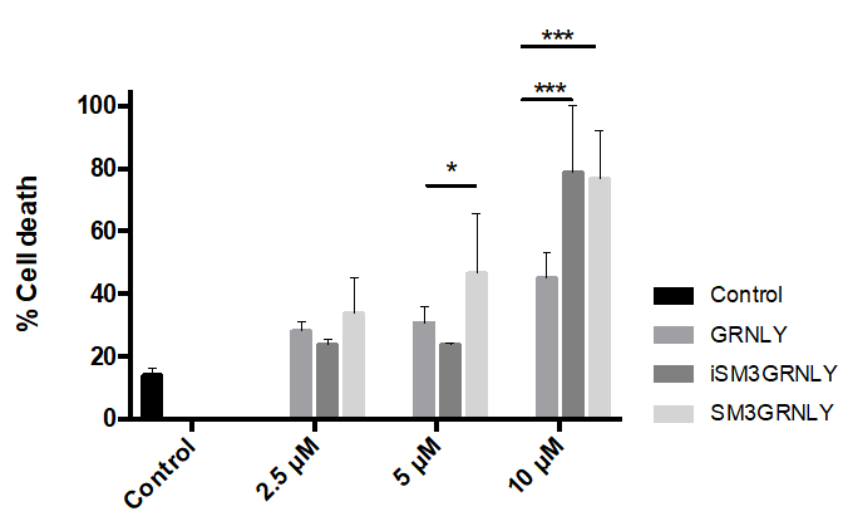

Figure 4. Dose-response cytotoxicity assays of GRNLY, SM3GRNLY and iSM3GRNLY on JURKAT cells. The cells were incubated with increasing concentrations of the recombinant proteins GRNLY (gray bars), iSM3GRNLY (dark gray bars) or SM3GRNLY (light gray bars) for $24 \mathrm{~h}$. GRNLY, SM3GRNLY and iSM3GRNLY induced cell death was determined by detection of PS translocation by Annexin-V-FITC labeling combined with size analysis; $\mathrm{p}^{*}<0.05, \mathrm{p}^{* *}<0.01, \mathrm{p}^{* * *}<0.001$.

As shown in Fig. 4, SM3GRNLY resulted significantly more cytotoxic against Jurkat cells than GRNLY alone at $5 \mu \mathrm{M}$. This higher cytotoxicity was shared by SM3GRNLY and iSM3GRNLY at $10 \mu \mathrm{M}$, demonstrating the increase in cytotoxicity given by antigen recognition by the $\mathrm{scFv}$ moiety.

Regarding AR20.5GRNLY, CAPAN-2 pancreatic adenocarcinoma cells were clearly more sensitive to the immunotoxin than to GRNLY alone (Fig 5). At $5 \mu \mathrm{M}$ and $10 \mu \mathrm{M}$, 
AR20.5GNLY was significantly more cytotoxic than GRNLY, reaching over $80 \%$ cell death at $10 \mu \mathrm{M}$. This correlates with the fact that CAPAN-2 is the cell line in which the highest binding of AR20.5GRNLY was found by flow cytometry (see Figure 3). In the case of the multiple myeloma NCI-H929, and although the binding of AR20.5GNLY was also high (Figure 3), the cytotoxicity of AR20.5GRNLY was not higher than that of GRNLY (Figure 5). This could be due to the fact that H929 cells are very sensitive to GRNLY cytotoxicity, as previously described both in vitro [17] and in vivo [15], being the targeting mediated by the scFv moiety unable to increase this cytotoxicity level. In A549 lung adenocarcinoma cells, AR20.5GRNLY resulted significantly more cytotoxic than GRNLY at low concentrations, 2.5 and $5 \mu \mathrm{M}$, although this level of cytotoxicity did not increase at 10 $\mu \mathrm{M}$, arriving at a maximum of $60 \%$ of cell death for both GRNLY and AR20.5GRNLY (Fig 5). In the MCF-7 breast adenocarcinoma, AR20.5GRNLY was more cytotoxic than GRNLY at $5 \mu \mathrm{M}$, but, as observed in A549 cells, this level of cytotoxicity did not increase at $10 \mu \mathrm{M}$ (Fig 5). Finally, MDA-MB-231 cells, a breast adenocarcinoma cell line negative for the expression of the Tn antigen, were not very sensitive to GRNLY, and this cytotoxicity did not increase when using AR20.5GRNLY, confirming the usefulness of this cell line as a negative control for Tn expression.
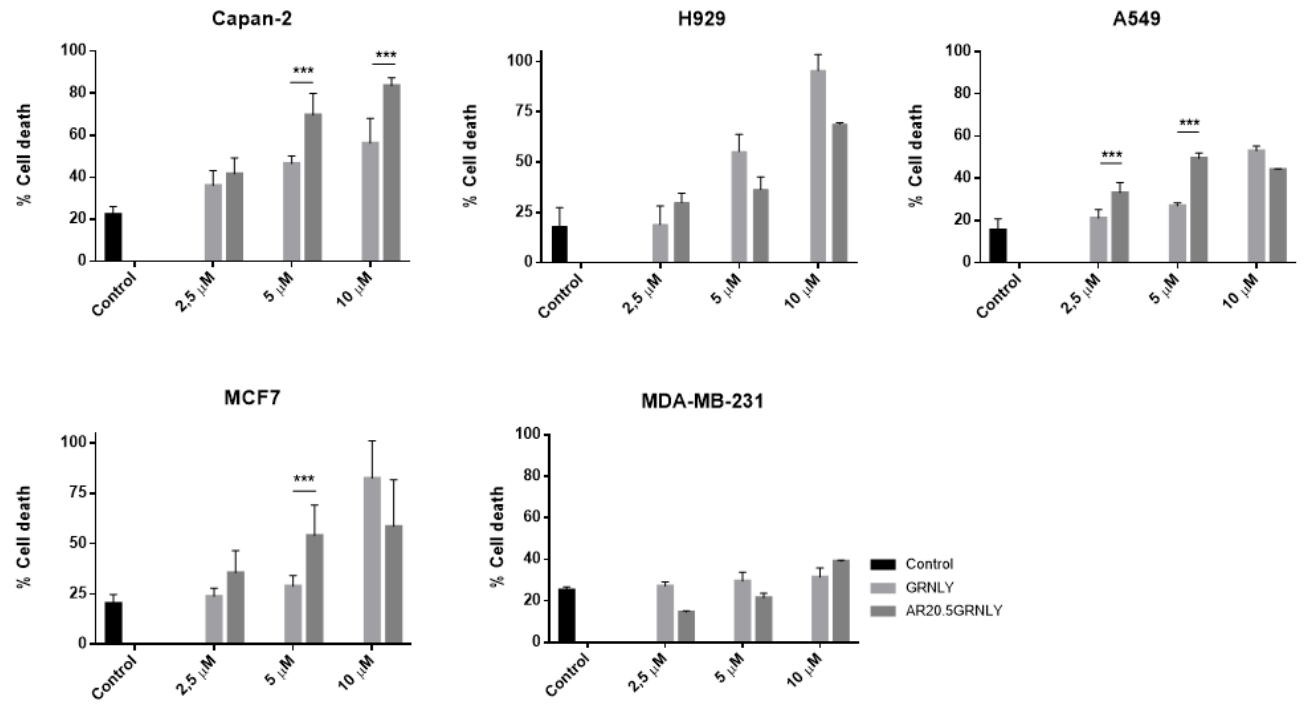

Figure 5. Dose-response cytotoxicity assays of GRNLY, iAR20.5GRNLY and AR20.5GRNLY in CAPAN-2, MCF-7, A549, H929 and MDA-MB-231 cells. Cells were incubated with increasing concentrations of recombinant GRNLY (gray bars), iAR20.5GRNLY (dark gray bars), or AR20.5GRNLY (light gray bars) for $24 \mathrm{~h}$. Cell death was determined by detecting PS exposure by Annexin-V-FITC labeling combined with size analysis (FSC-H); $\mathrm{p}^{*}<0.5, \mathrm{p}^{* *}<0.01, \mathrm{p}^{* * *}<0.001$.

\subsection{Mechanism of cell death induced by SM3GRNLY}

The GRNLY mechanism of cell death induction was previously shown to be mediated by the mitochondrial apoptotic pathway, although in some cell lines, and especially if caspases were inhibited, a minor necroptotic component could be also observed [17, 26]. 
In this work, we have studied the mechanism of cell death induced in tumor cells by the anti-Tn immunotoxin SM3GRNLY. For that, we first tested SM3GRNLY on Jurkat cells in which pro-apoptotic Bak was deleted by small hairpin technology, generating the Jurkat-shBak cell line. Jurkat cells do not express Bax, so Jurkat-shBak cells are unable to activate the mitochondrial apoptotic pathway [27]. A comparative time course was performed with a $10 \mu \mathrm{M}$ concentration of each protein in Jurkat cells, Jurkat cells transfected with the empty vector used to generate the Bak-deficient subline, Jurkat -pLVTHM cells, or Jurkat-shBak cells. As shown in Figure 6A, the cytoxicity of GRNLY is similar on Jurkat and on Jurkat-pLVTHM cells and this toxicity is almost totally abolished in Jurkat-shBak cells. In the case of SM3GRNLY, its toxicity was higher than that of GRNLY on Jurkat and on Jurkat-pLVTHM cells and, although lower, it was not eliminated on Jurkat-shBak cells, suggesting the activation of a cell death mechanism independent of the mitochondrial apoptotic pathway. To confirm these results, we also performed a dose-response test of SM3GRNY and GRNLY on the pancreatic adenocarcinoma cell line MIA PACA-2 and on its derivative in which Bax and Bak were silenced, MIA PACA-2-KO. Confirming the data obtained with the Jurkat model, while the cytotoxic effect of GRNLY was highly compromised in MIA PACA-2-KO cells, that of SM3GRNLY was almost not affected (see Figure 6B).

A

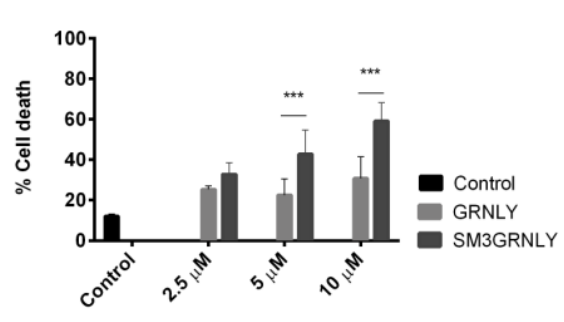

MIA PACA-2 KO

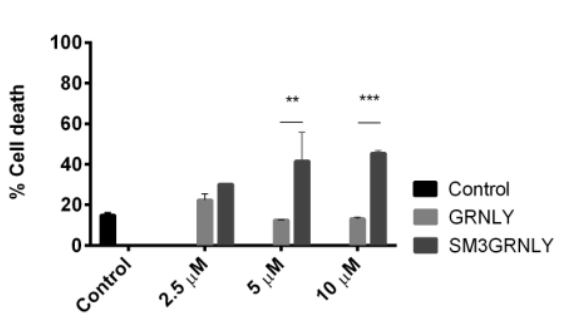

B

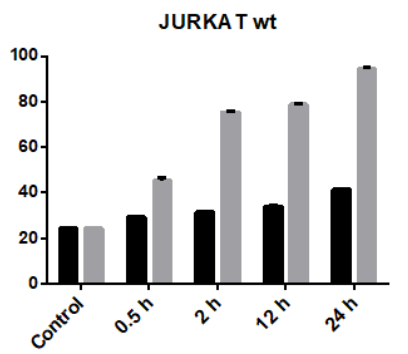

JURKA T PIVTHM

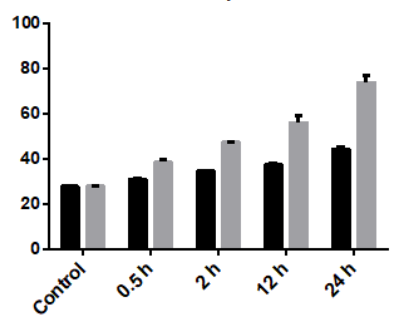

GRNLY SM3GRNLY

Figure 6. Dose-response cytotoxicity assays of GRNLY and SM3GRNLY on Jurkat, Jurkat-plvTHM and Jurkat-shBak cells (A) or on MIA PACA-2 and MIA PACA-2 KO cells (B). A, cells were incubated with a $10 \mu \mathrm{M}$ concentration of GRNLY (grey bars) or of SM3GRNLY (black bars) during the times indicated; B, cells were incubated with increasing concentrations of recombinant GRNLY (gray bars) or SM3GRNLY (black bars) for $24 \mathrm{~h}$. After the incubations, cell death was determined by detecting PS exposure by Annexin-V-FITC labeling and analysis of cell size by FSC. Results are the mean \pm SD of three independent experiments; $\mathrm{p}^{*}<0.5, \mathrm{p}^{* *}<0.01, \mathrm{p}^{* * *}<0.001$.

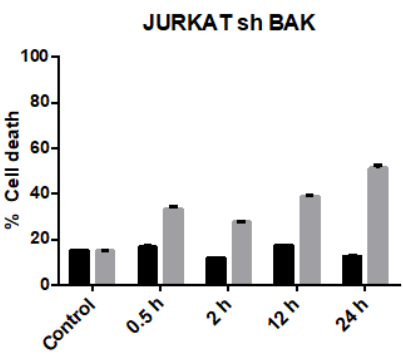



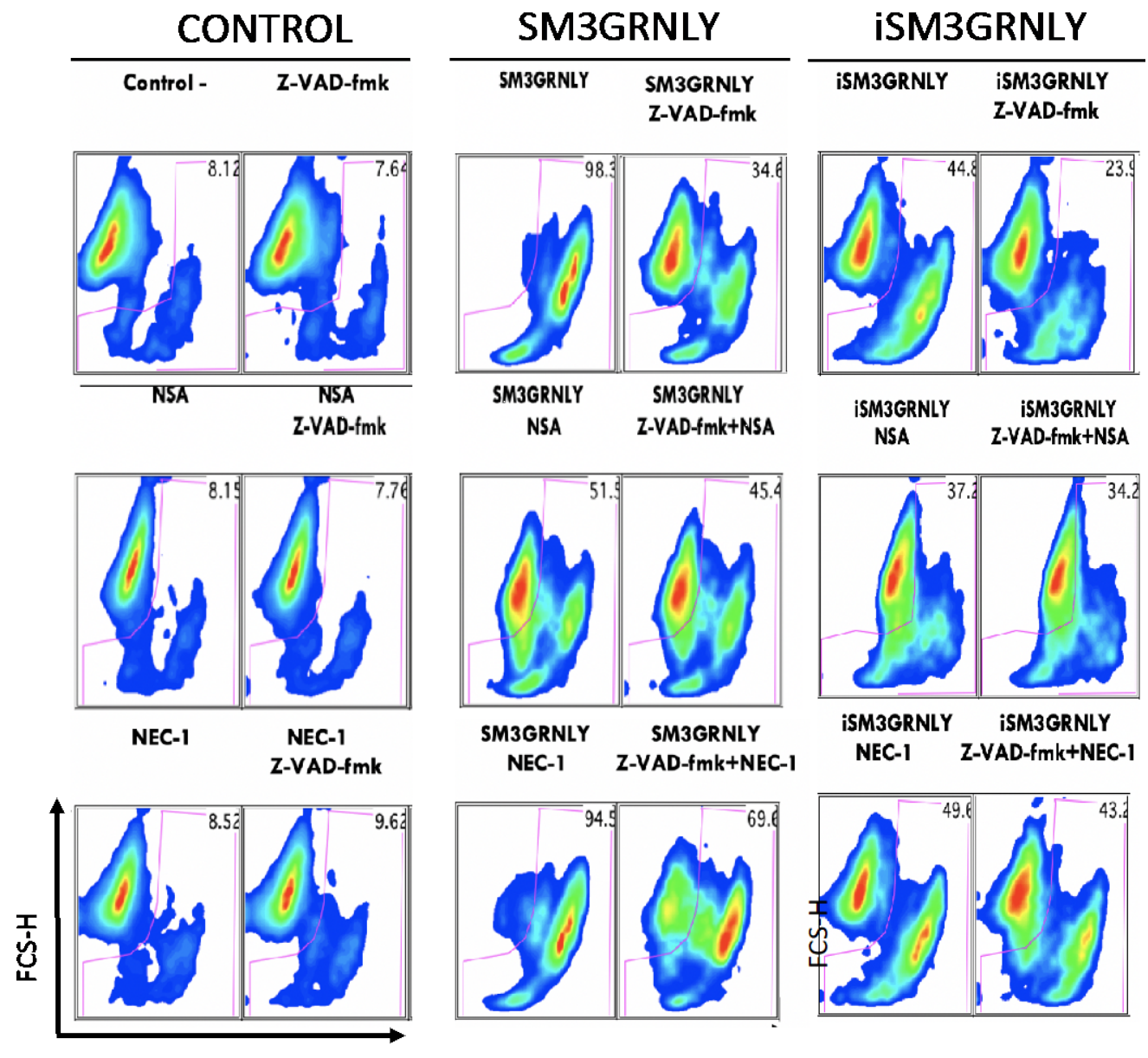

Annexin-V-FITC

Figure 7. Study of the induction of death in JURKAT cells. Cells were preincubated for $1 \mathrm{~h}$ in the presence or absence of $100 \mu \mathrm{M} Z$-VAD-fmk, $30 \mu \mathrm{M}$ NEC-1 or $1 \mu \mathrm{M}$ NSA alone or in combination. Subsequently, they were incubated with $10 \mu \mathrm{M}$ of SM3GRNLY for $24 \mathrm{~h}$ and analyzed by flow cytometry by labeling with Annexin-V-FITC combined with the analysis of cell size in FSC-H. Representative images from two independent experiments are shown.

Another strategy to study the mechanism of death induction by SM3GRNLY was the use of inhibitory molecules of known death pathways. The general caspase inhibitor Z-VAD-fmk significantly, although only partially, prevented death induced by SM3GRNLY (from 98\% to 34\%), while the RIP1 inhibitor, necrostatin 1 (NEC-1) had no effect either alone or in combination with Z-VAD-fmk (Fig 7). The MKLK inhibitor $\mathrm{N}$-sulfonamide (NSA) partially prevented the death induced by SM3GRNLY (from 98\% to $51 \%$ ) and this inhibition increased when combined with Z-VAD-fmk up to $45 \%$. However, inhibition was not complete in any case. These results suggest that, while GRNLY exerts tumor cell death following the classical caspase dependent, mitochondrial apoptotic pathway, SM3GRNLY-induced cell death implicates both apoptotic and necroptotic pathways, together with a rather necrotic component. Similar results were obtained for iSM3GRNLY (see Supplementary Figure S2)

\subsection{In vivo demonstration of immunotoxin targeting after systemic injection}

The main objective of granulysin-based immunotoxin design was to demonstrate that they are able to target the toxic moiety towards Tn-expressing tumors after systemic injection in vivo. 
For that, we first selected the Tn-expressing cell line for conducting in vivo assays attending to three parameters:

i) tumor development in a reasonable time after injection in athymic mice

ii) high immunotoxin binding

iii) increase in cytotoxicity of the immunotoxins as compared with GRNLY

For example, although the immunotoxins bound with high intensity to Jurkat and Panc-1 cells ([21] and Fig 3), indicative of a high Tn antigen expression, these cells did not generate tumors in athymic mice after s.c. injection of $10 \times 10^{6}$ cells for more than three months, so these cell lines were discarded for in vivo experiments. The cell line that best attained the three parameters was the pancreatic adenocarcinoma Capan-2. This cell line generated detectable tumors in athymic mice between 10 and 20 days after injection of $5 \times 10^{6}$ cells in Matrigel; the binding of SM3GRNLY, iSM3GRNLY and especially of AR20.5GRNLY to this cell line is maximal (Suppl. Tables $1 \& 2$ and Figure 3); and while the IC50 for GRNLY was $10 \mu \mathrm{M}$, it was reduced to $5 \mu \mathrm{M}$ for SM3GRNLY and iSM3GRNLY [21] and to $2.5 \mu \mathrm{M}$ for AR20.5GRNLY (Fig 5). Hence, Capan-2 was selected to perform the in vivo assays of the immunotoxins compared with GRNLY. This is especially interesting, given the bad prognosis of pancreatic adenocarcinoma and the lack of efficient treatments.

The protocol followed in these experiments is shown in the upper panel of Fig 8 and described in the Materials and Methods section. As shown in the middle upper panel of Figure 8, the inhibition of tumor growth by systemic injection of GRNLY was not significant at any time point. However, SM3GRNLY was effective in inhibiting the growth of Capan-2-derived tumors, with the effect being statistically significant from the fifth injection of the treatment. The inhibition of tumor growth by SM3GRNLY at the time of sacrifice was $42 \%$ (lower middle panels of Figure 8 ). When analyzing the tumor weights and volumes of resected tumors (bar graphics), the SM3GRNLY inhibition of tumor growth was also statistically significant and accounted for 40 and 33\% of inhibition, respectively.

Regarding AR20.5GRNLY, and due to the above-described problems of production, we could only produce recombinant pure protein to treat one mouse, so the results do not have statistical significance. As shown in the lower panels of Fig 8, AR20.5GRNLY substantially reduced tumor growth in this mouse, arriving to $60 \%$ of tumor growth inhibition at the time of sacrifice. 

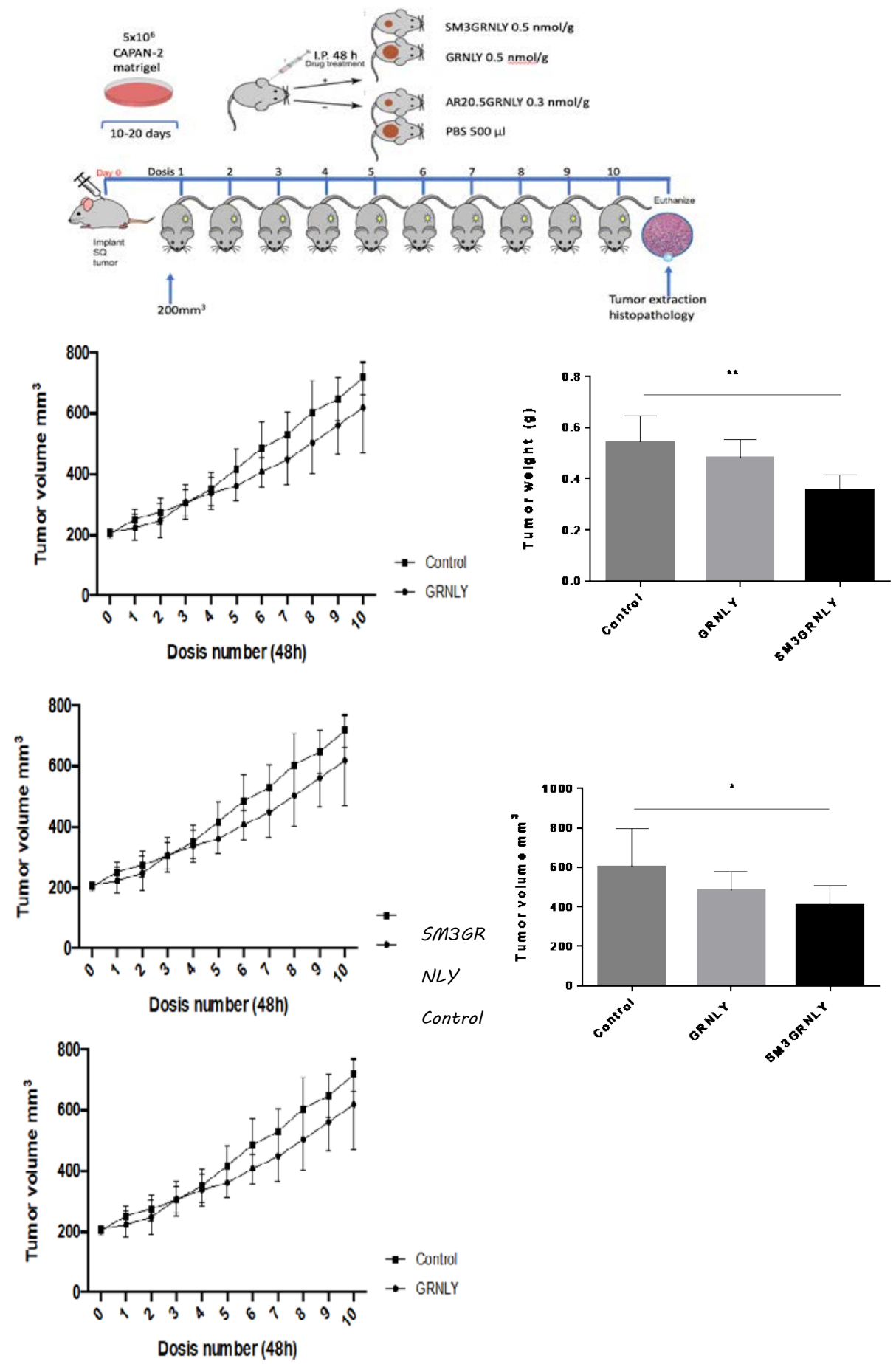

Figure 8. Systemic treatment of xenograft nude mice with CAPAN-2 cells. The mice in each group received intraperitoneal injections of the respective treatments every $48 \mathrm{~h}$ for 10 occasions and two days after the last dose, the animals were sacrificed. Data are the mean \pm SD of tumor volume in each study group. AR20.5GRNLY allowed to treat 1 mouse (statistical analysis could not be performed). ${ }^{* *}, \mathrm{P}<0.01 ;{ }^{* * *}, \mathrm{P}<0.001$. 

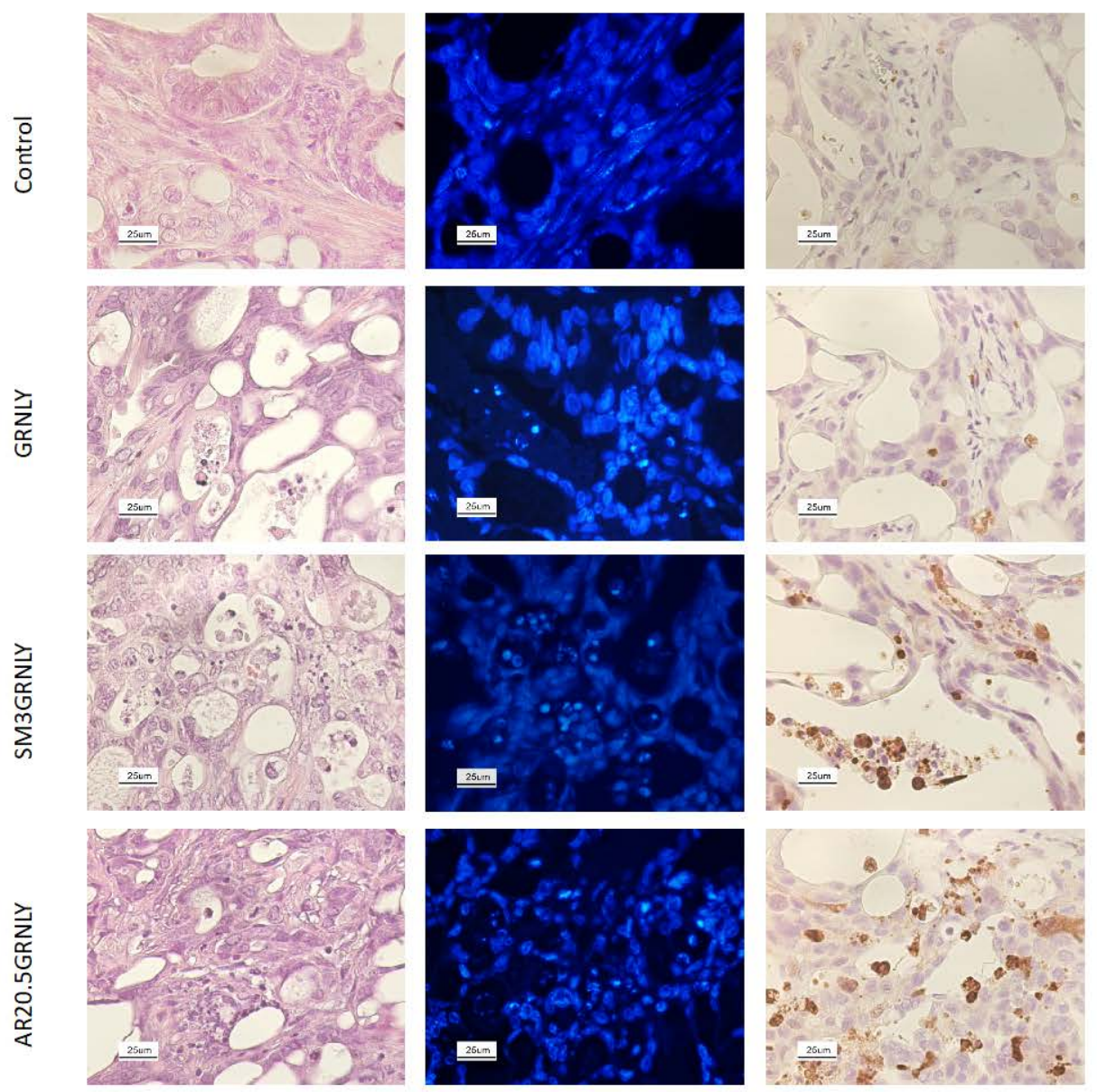

Figure 9. Hematoxylin-Eosin staining (left), DAPI nuclear staining (middle) and Activated Caspase-3 Immunohistochemistry (right) of tumors derived from CAPAN-2 xenografts. Representative images of histological sections of tumors treated with PBS (first row), GRNLY (second row), SM3GRNLY (third row) and AR20.5GRNLY (fourth row). Image magnification was used at 400x.

After tumor resection, we performed histological analysis of tumors obtained from treated or untreated mice. As shown in the left panels of Fig 9, the hematoxilin/eosin staining of tumors obtained from control mice showed high cellularity and the presence of acinar structures, typical of this type of glandular tumor. However, in the sections of tumors obtained from mice treated with SM3GRNLY or AR20.5GRNLY, cellularity is reduced and the glandular acinar spaces are disorganized. In addition, abundant fragmented apoptotic nuclei and leukocyte infiltration are distinguished, especially in the case of AR20.5GRNLY treatment.

Nuclear staining in tumor sections was performed using the DAPI fluorescent molecule and representative images are shown in the middle panels of Fig 9. Tumors obtained from mice treated with SM3GRNLY or AR20.5GRNLY showed chromatin condensation and nuclear fragmentation, typical of apoptotic cell death, a pattern that was absent in the tumors of untreated mice and scarce in the tumors of mice treated with GRNLY.

To further ascertain apoptosis induction in tumors from treated mice, we determined activated caspase- 3 in the tumor tissue by immunohistochemistry. While no active caspase- 3 was detected in tumors from control mice, and very scarce staining was obtained in tumors from mice treated with GRNLY, brown stained cells was very apparent in tumors obtained from mice treated with SM3GRNLY or AR20.5GRNLY. 


\section{Discussion}

The antibacterial and antiparasitic function of $9 \mathrm{kDa}$ GRNLY has long been known, a property that has been confirmed and expanded in recent studies [28-30]. Our group has shown that recombinant GRNLY is capable of killing tumor cells in vitro through the mitochondrial apoptotic pathway $[17,18,26]$. This antitumor activity of recombinant GRNLY was also demonstrated in vivo, initially by intratumoral injection in several tumors types: mammary carcinoma, multiple myeloma and melanoma $[15,16]$. There are abundant data that relate granulysin expression to an active antitumor immune response and to a good prognosis [31-34]. Although mice do not express a granulysin homologue, the Alan Krensky group generated transgenic mice that expressed human granulysin and showed an increased resistance to tumor development [35].

However, systemic treatment of tumors would require improving the directionality of the molecule. This can be achieved by the conjugation of an antibody or antibody fragment directed against a tumor molecule with GRNLY, generating a so-called fourth-generation immunotoxin [20]. Our team designed three immunotoxins that conjugated GRNLY with scFv, one directed against CEA (Carcino-embryonic antigen) [19], and two against the Tn antigen [21]. CEA or CEACAM5 is a tumor antigen expressed preferentially by colorectal or gastric tumors [36]. The Tn antigen is an aberrant glycosylation of the surface protein MUC-1 and is expressed by a wide variety of tumors [2, 3]. The systemic administration of the anti-CEA immunotoxin, called MFE23GRNLY, has shown directionality against tumors positive for CEA expression and cytotoxic capacity superior to GRNLY in a murine model [19] constituting the proof of concept of this new anti-tumor treatment.

The efficiency of electroporation by PEF showed that a high percentage of the two anti-Tn used in this work, SM3GRNLY and AR20.5GRNLY, was retained inside yeasts, which was not the case with the GRNLY or MFE23GRNLY producing strains, in which most of the protein is secreted by yeasts to the supernatant (Raquel Ibáñez, personal communication). The use of the PEF technique has allowed to perform the in vivo experiments shown, which need higher amounts of the recombinant proteins [21].

According to the SRP assays, immunotoxins retained the ability to recognize and bind its antigen with a similar affinity that was described previously for the scFv fragments alone. The ability to bind to the Tn antigen expressed on the surface of living tumor cells was also demonstrated in cell lines in which the expression of the Tn antigen had been described: pancreatic adenocarcinomas PANC-1, CAPAN-2 [37], MCF-7 breast adenocarcinoma [38], A549 lung adenocarcinoma [39] and Jurkat acute lymphocytic leukemia [25], using MDA-MB-231 mammary adenocarcinoma as a negative control [22]. In general, this recognition was of greater intensity, and in a greater number of cell lines, with the immunotoxin AR20.5GRNLY with respect to SM3GRNLY and iSM3GRNLY. It should be noted that our immunotoxins recognize the Tn antigen by flow cytometry more efficiently than commercial anti-Tn antibodies (see Supplementary Figure 1).

The binding of the anti-Tn immunotoxins used in this work to its antigen, purified or expressed on the surface of tumor cells was correlated with a higher cytotoxicity on different cell lines positive for the expression of Tn compared with recombinant GRNLY alone. We also demonstrate that these immunotoxins exert cytotoxicity on tumor cells by combining several cell death mechanisms: apoptosis, necroptosis and necrosis. More importantly, these immunotoxins demonstrated directionality of the treatment after systemic injection, reducing the tumor volume of xenotransplants of CAPAN-2 human pancreatic adenocarcinoma in athymic mice, whereas recombinant GRNLY alone was not effective. Tumor size reduction was associated with induction of apoptosis in the tumor tissue, demonstrated by nuclear morphology analysis and in-tissue caspase- 3 activation. 
The mechanism by which granulysin results cytotoxic against tumor cells is mediated by the interaction of its positive charges with negatively charged membrane phospholipids [40]. This interaction is dependent on the presence of a net negative charge of the tumor cell membrane and is reduced when the cholesterol/phospholipid ratio increases. This explains why granulysin is especially active on lipid membranes of microorganisms devoid of cholesterol, such as bacterial membranes, and less active on eukaryotic lipid membranes [41]. However, the cholesterol/phospholipid ratio of tumor cells is highly reduced as compared with that of their healthy counterparts [42, 43], explaining the tumor selectivity of granulysin $[26,44]$. Although granulysin, contrary to perforin, is not able to induce the formation of pores in the membrane, its interaction with phospholipids induces alterations of the membrane structure enough to alter the cellular ionic equilibrium [40], resulting in a net increase the cytoplasmic $\mathrm{Ca}^{2+}$ concentration [17, 45]. This increase in the cytoplasmic $\mathrm{Ca}^{2+}$ concentration causes the generation of mitochondrial ROS that leads to the loss of mitochondrial membrane potential and release of the apoptogenic molecules cytochrome $\mathrm{c}$ and AIF from mitochondria, initiating the mitochondrial apoptotic pathway and caspase-independent cell death, respectively [17, 45, 46]. When granulysin is acting in concert with perforin, the mechanism of cell death induction is rather dependent of ER stress and seems to activate a different set of executor caspases [47].

The membrane-based activity of recombinant granulysin or of granulysin-based immunotoxins constitutes a new immunotoxin mechanism of action, that is non-dependent on internalization and release from the endosome, one of the major caveats of immunotoxin use, including granzyme B-based $4^{\text {th }}$ generation immunotoxins [48]. On the other hand, since granulysin is a human protein, granulysin-based immunotoxins will be devoid of the immunogenicity that normally exhibit toxins of bacterial or plant origin [20,49].

Remarkably, the antitumor activity of granulysin was associated with a massive NK cell infiltration, suggesting a possible immunogenic effect of granulysin-induced tumor cell death $[15,16]$. In addition, no side effects of this type of treatment were detected in those in vivo experiments [15].

Together with our previous study using the anti-CEA immunotoxin MFE23GRNLY [19], the present work opens the door to the use of granulysin-based immunotoxins for cancer treatment, expanding also its application to a broader spectrum of cancer types in the case of immunotoxins directed against the Tn antigen.

\section{Materials and Methods}

\subsection{Bacterial Strains, Plasmids, and Culture Conditions}

Synthetic genes encoding 6xHis-tagged $9 \mathrm{kDa}$ granulysin, SM3GRNLY or AR20.5GRNLY were synthesized by Geneart GmbH (Thermo Fisher Scientific, Regensburg, Germany) and subcloned as ClaI/XbaI or NruI/XbaI into pCR3.1-NC145 resulting in pCR3.1-GRNLY, pCR3.1-SM3GRNLY, and pCR3.1-AR20.5GRNLY, respectively. The ClaI/XbaI-digested fragments of pCR3.1-GRNLY, pCR3.1-SM3GRNLY, and pCR3.1-AR20.5GRNLY were ligated into the ClaI/XbaIdigested backbone of plasmid pPICZ $\alpha$ to obtain pPICZ $\alpha C-G R N L Y$ and pPICZ $\alpha A-S M 3 G R N L Y$ or pPICZ $\alpha$ A-AR20.5GRNLY. The E. coli DH5 strain was grown at $37^{\circ} \mathrm{C}$ in Luria-Bertani medium (LB; Oxoid, Basingstoke, UK). Pichia pastoris was grown at $30^{\circ} \mathrm{C}$ in yeast extract with peptone and dextrose (YPD) broth (Formedium) for routine maintenance and in buffered glycerol-complex medium (BMGY) (1\% yeast extract, 2\% peptone, 1.34\% yeast nitrogen base (YNB) 1\% glycerol, $400 \mathrm{~g} / \mathrm{L}$ biotin, and $0.1 \mathrm{M}$ potassium phosphate, $\mathrm{pH}$ 6.0) for expansion and big-scale production, followed by cultured at $18^{\circ} \mathrm{C}$ in buffered 
methanol-complex medium (BMMY) (1\% yeast extract, $2 \%$ peptone, $1.34 \% \mathrm{YNB}, 1 \%$ methanol, $400 \mathrm{~g} / \mathrm{L}$ biotin, and $0.1 \mathrm{M}$ potassium phosphate, $\mathrm{pH}$ 6.0) for induction of the recombinant protein. The synthetic gene encoding 6xHis-tagged $9 \mathrm{kDa}$ granulysin was synthesized and inserted in the $p$ PICZ $\alpha A$ plasmid as indicated in Ibáñez 2019. The synthetic gene coding for 6xHis-tagged SM3GRNLY was synthesized and inserted in the pPICZ A plasmid by Genscript (Leiden, The Netherlands). Both plasmids were amplificated in E. coli and isolated by Nucleo SpinPlasmid EasyPure (Macherey-Nagel). Plasmids were linearized with SacI (Takara) and purified by Ilustra GFX PCR DNA and Gel Band Purification kit (GE Healthcare). The transformation of $P$. pastoris and the selection of transfected colonies was performed by the methods described in [19].

\subsection{Expression and Purification of Extracellular Recombinant GRNLY and immunotoxins in Pichia Pastoris}

The pre-inoculum of P. pastoris cell strains X33 for SM3GRNLY and SMD1168 for GRNLY, was cultured in $100 \mathrm{~mL}$ YPD medium overnight at $30^{\circ} \mathrm{C}$ for activation; the cells were then added to $1000 \mathrm{~mL}$ of BMGY medium, incubated overnight at $30^{\circ} \mathrm{C}$ for growth and finally in BMMY medium at $18^{\circ} \mathrm{C}$ for induction. All these culture steps were performed in a thermostated shaking incubator at $250 \mathrm{rpm}$ as shaking intensity. The culture was fed with $1 \%$ methanol every $24 \mathrm{~h}$ for 2 or 3 days; then the culture was centrifuged 30 min and the supernatant was incubated with $\mathrm{Ni}^{2+}$ affinity chromatography (Ni-NTA-agarose overnight-Invitrogen) and eluted with buffer Imidazol $250 \mathrm{mM}$ in PBS. The eluate was concentrated and its buffer was changed to PBS using Amicon filters (MerckMillipore).

5.3. Expression and Purification of Intracellular Recombinant Immunotoxins from Pichia Pastoris by Pulsed Electric Field Technology

The PEF equipment used in this work was the commercial model EPULSUS -PM1-10 (Energy Pulse System, Lisbon, Portugal). P. pastoris cells were resuspended in Mcllvaine buffer $(\mathrm{pH} 7.0$ and $1.50 \mathrm{mS} / \mathrm{cm}$ ) at a concentration of around 108 cells $/ \mathrm{mL}$ and PEF-treated in continuous flow $(5.0 \mathrm{~L} / \mathrm{h}$ ) in parallel electrode chamber of 3.0 $\mathrm{cm}$ length, $0.50 \mathrm{~cm}$ width and a gap of $0.40 \mathrm{~cm}$. The calculated mean residence time in the treatment chamber was $0.40 \mathrm{~s}$. A heat exchanger consisting of a coil submerged in a thermostatic batch was used to set the initial temperature of the yeast before the treatment at $10^{\circ} \mathrm{C}$. The temperature of the yeast suspension after the PEF treatment chamber never exceeded $30^{\circ} \mathrm{C}$. P. pastoris cells were treated at electric field strength between 8 and $20 \mathrm{kV} / \mathrm{cm}$ for treatment times between 150 and $180 \mu \mathrm{s}$. After the treatments, serial decimal dilutions were poured plated in potato dextrose agar in order to monitor P. pastoris cell inactivation. The number of viable cells was expressed in colony-forming units (CFU), corresponding to the number of colonies counted after $48 \mathrm{~h}$ of incubation at $25^{\circ} \mathrm{C}$. Inactivation data were expressed as the ratio between the initial number of survivors (No) and the number of survivors after different treatment times $(\mathrm{Nt})$. Release of protein from untreated and PEF-treated (12, 16 and $20 \mathrm{kV} / \mathrm{cm}$ for 15 to $180 \mu \mathrm{s})$ cells of P. pastoris was monitored after $180 \mathrm{~min}$ of incubation at $20^{\circ} \mathrm{C}$ in a Mcllvaine buffer solution of $\mathrm{pH} 7$ and $1 \mathrm{mS} / \mathrm{cm}$ of conductivity. Quantitative analysis of released proteins was conducted by the microplate procedure of Pierce BCA Protein Assay Kit (Thermo Scientific, Rockford, IL 61105, USA) [21].

\subsection{Surface Plasmon Resonance}

SPR experiments were performed with a Biacore X-100 apparatus (Biacore, GE) in HBS-EP buffer at pH 7.5 (Hepes $10 \mathrm{mM}, \mathrm{NaCl} 150 \mathrm{mM}$, EDTA $3 \mathrm{mM}$, with $\%$ DMSO and $0.05 \%$ Tween X100 as the running buffer at $25^{\circ} \mathrm{C}$. The SM3GRNLY and AR20.5GRNLY immunotoxins were immobilized on a CM5 sensor chip (Biacore, GE) following standard amine coupling method. Briefly, the carboxymethyl dextran surface of the flow cell 2 was activated with a 7-min injection of a 1:1 ratio of aqueous $0.4 \quad \mathrm{M}$ 
1-ethyl-3-(3-dimethylaminopropyl) carbodiimide (EDC) and $0.1 \quad \mathrm{M}$ sulfo-N-hydroxysuccinimide. Then, the SM3GRNLY and AR20.5GRNLY immunotoxins was coupled to the surface during a 7-min injection using several dilutions in $10 \mathrm{mM}$ sodium acetate, $\mathrm{pH}$ 4.0. The unreacted active esters on the surface were quenched by a 7-min injection of aqueous $0.1 \mathrm{M}$ ethanolamine- $\mathrm{HCl}(\mathrm{pH} 8.0)$. The levels of immobilization were 5700 resonance units (RU) for SM3GRNLY and 6800 RU for AR20.5GRNLY. Flow cell 1 treated as a flow cell 2 (amine coupling procedure) without protein was used as a reference. Prior to use, $50 \mathrm{mM}$ stock solutions of peptide ligand MUC21T were diluted to the final concentration in the running buffer. Typically, a series of different compounds was injected onto the sensor chip a flow rate of $30 \mu \mathrm{l} / \mathrm{min}$ for a period of $1 \mathrm{~min}$ followed by a dissociation period of $1 \mathrm{~min}$. No regeneration was needed. The concentrations used for affinity measurements were in the range of 0.05-4 mM. Sensogram data were double-referenced using the Biaevaluation X-100 software (Biacore, GE). The experimental data of affinity measurements were fitted to a one site-specific model binding using Prism software.

\subsection{Cell culture}

The acute lymphoblastic leukemia Jurkat and multiple myeloma H929 cells, obtained from the ATCC, were cultured in RPMI 1640 medium supplemented with 5\% FBS (Pan Biotech, Aidenbach, Germany) at $37^{\circ} \mathrm{C}$ and $5 \% \mathrm{CO}_{2}$ using standard procedures. The pancreas ductal adenocarcinomas CAPAN-2 and PANC1, the lung adenocarcinoma A549 and the breast adenocarcinoma MDA-MB-231 were cultured in DMEM medium (Pan Biotech $\mathrm{GmbH}$ ) supplemented with 10\% FBS (Sigma). In all cases, culture media were supplemented with penicillin/streptomycin (Pan Biotech) and GlutaMAX (Invitrogen, Barcelona). All cell lines were routinely tested for mycoplasma contamination by PCR.

\subsection{Binding of immunotoxins to the Tn antigen analyzed by flow cytometry}

To analyze binding to the Tn antigen on the surface of living cells, $10^{5}$ cells per well were placed in a 96-well round bottom plate. First, cells were incubated with or without SM3GRNLY, iSM3GRNLY or AR20.5GRNLY $(10 \mu \mathrm{g} / \mathrm{ml})$ in PBS $5 \%$ FBS for $30 \mathrm{~min}$ at $4^{\circ} \mathrm{C}$ followed by mouse anti-histidine tag antibody (1:200; Genscript, Netherlands) and goat anti-mouse antibody bound to FITC (1:200; Caltag, Barcelona). After each incubation, cells were washed with 5\% FBS in PBS. Binding was determined using a FACScalibur flow cytometer (BD Biosciences) using as controls cells treated in the same way but in the absence of the incubation with the immunotoxin.

\subsection{In vitro cytotoxicity assays}

$50 \mu \mathrm{l}$ aliquots of $1 \times 10^{6} / \mathrm{ml}$ cell suspensions in complete medium were seeded per well in 96 well plates and GRNLY or the immunotoxins were added at the indicated concentrations. In control wells, the same volume of PBS was added. Cells were then incubated for $24 \mathrm{~h}$ at $37^{\circ} \mathrm{C}$ and cell death was analyzed by determination of phosphatidylserine exposure by flow cytometry after incubation with Annexin V-DY634, produced as described by Logue et al. [50] or with 7-AAD in annexin binding buffer $(140 \mathrm{mMNaCl}, 2.5$ $\mathrm{mM} \mathrm{CaCl}_{2}, 10 \mathrm{mM}$ Hepes/NaOH, pH 7.4) for 15 minutes. Cell death was estimated using a simultaneous determination of FITC or 7-AAD labelling and cell size by forward scatter (FSC).

\subsection{In vivo assays}

Immune-deficient athymic mice, Swiss nu/nu strain, six-week old males (Charles River), were used in this study. Mice experiments were performed according to the European recommendations on animal ethics and the University of Zaragoza Animal Experimentation Ethical Commission previously approved the housing and experimental protocols. Mice were kept under specific standard pathogen-free conditions (average ambient temperature $24^{\circ} \mathrm{C}, 12 / 12 \mathrm{~h}$ light/dark cycle) with water and food provided ad 
libitum throughout the study. Tumor growth was analyzed by measuring the tumor daily with a precision caliper. To calculate the tumor volume, the width (A) and length (L) of the tumor were measured, and the following formula was applied:

$$
\mathrm{V}=\mathrm{L} \times \mathrm{A}^{2} / 2
$$

At the end of the experiment ( 2 days after the last injection) mice were euthanized and the tumors were surgically excised, fixed in $10 \%$ buffered formalin and embedded in paraffin. For systemic treatments, $5 \times 10^{6} \mathrm{CAPAN}-2$ tumor cells suspended in Matrigel were injected subcutaneously in nude mice ( $\mathrm{n}=5$ mice per group). When the tumors reached a mean volume of $0.2 \mathrm{~cm}^{3}$, mice were treated with intraperitoneal injections of 0.5 $\mathrm{nmol} / \mathrm{gr}$ mouse weight of GRNLY or SM3GRNLY or with $0.2 \mathrm{nmol} / \mathrm{gr}$ mouse weight of AR20.5GRNLY i.p. every 2 days for 10 times. Mice in the control group received injections of PBS with the same time schedule.

\subsection{Histology analysis}

Tissue sections $5 \mu \mathrm{m}$ thick were deparaffinated, rehydrated and stained by immersing in GILL II Hematoxylin, followed by eosin staining. For the study of apoptotic nuclei, tissue sections were stained with DAPI Fluoromont-G (EMS, Madrid) for $10 \mathrm{~min}$ and detected in a fluorescence microscope (E600/E400, Nikon) equipped with a digital photography machine (DXM1200F, Nikon). The expression of activated caspase-3 was investigated by immunohistochemistry using a rabbit polyclonal anti-human caspase-3 antibody (Cell Signaling, Barcelona), which recognizes the active, cleaved caspase-3 form. For antigen retrieval, the sections were boiled in $10 \mathrm{mM}$ citrate buffer, $\mathrm{pH} 6.0$ for 30 minutes. After blocking with 5\% horse serum diluted in PBS for $1 \mathrm{hr}$ at room temperature, sections were incubated at $4 \mathrm{C}$ in humid chambers with the anti-caspase- 3 antibody at $1 / 150$ dilution for $1 \mathrm{~h}$ followed by ready to use secondary anti-rabbit antibody (Vector Laboratories, Peterborough, UK) for $30 \mathrm{~min}$. As a chromogenic substrate, DAB (Agilent, Madrid) was used, followed by hematoxylin counterstaining. Appropiate negative control stainings were also performed.

\subsection{Statistical analysis}

Computer-based statistical analysis was performed using GraphPad Prism 4.0 program (GrandPath Software Inc). Results are shown as mean SD. Statistical significance was evaluated by using Student $\mathrm{t}$ test for non-paired variants. Differences were considered significant if $p<0.05$.

Author Contributions: Conceptualization, PGO, JR, RHG and AA.; methodology, FC, IM and JR.; investigation, PGO, RIP, GBP, DA and FC.; resources, FC, IM and JR.; data curation, PGO, RHG and AA.; writing - original draft preparation, PGO and AA; writing-review and editing, IM, FC, JR and RHG; visualization, PGO and AA; supervision, AA.; project administration, AA; funding acquisition, JR, RHG and AA. All authors have read and agreed to the published version of the manuscript.

Funding: This work was supported by Peaches Biotech through the contract 2020/0396 with the OTRI from University of Zaragoza. It was also financed by the Ministry of Economics and Competitivity of Spain (CTQ2013-44367-C2-2-P and BFU2016-75633-P grants to RHG; RTI2018-099592-B-C21 grant to FC), and by Government of Aragon (B31_20R to AA and E34_17R to RHG), co-financed by FEDER 2014-2020 "Builiding Europe from Aragon". The authors would also like to acknowledge the support of ARAID. PGO was supported by a Senescyt fellowship from the Government of Ecuador and RIP was supported by a predoctoral fellowship from Government of Aragon.

Institutional Review Board Statement: The study was approved by the Ethics Committee for Animal Experimentation of the University of Zaragoza (protocol code PI72/20; date of approval 01/11/21). 
Informed Consent Statement: Not applicable

Data Availability Statement: The data presented in this study are available on request from the corresponding author.

Acknowledgments: The authors thank Amparo Gallur, Alba de Martino y Cindy Giraldo, from the Microscopy and histopathology Core Unit, Institute for Health Sciences of Aragon (Zaragoza, Spain), for their advice and technical support.

Conflicts of Interest: The use of granulysin immunotoxins as an anti-tumoral treatment is protected by the patent application PCT/ES2018/P201830768 presented to the Spanish Bureau of Patents and Brands (OEPM) on 07/26/2018; international application number PCT/EP2019/069979; number of publication WO 2020020978 A1.

\section{References}

1. Nath, S.; Mukherjee, P., MUC1: A multifaceted oncoprotein with a key role in cancer progression. Trends Mol Med 2014, 20, 332-342.

2. Ju, T.; Otto, V.; Cummings, R., The Tn antigen-structural simplicity and biological complexity. Angew Chem Int Ed Engl 2011, 50, 1770-1791.

3. Martínez-Sáez, N.; Castro-López, J.; Valero-González, J.; Madariaga, D.; Compañón, I.; Somovilla, V.; Salvadó, M.; Asensio, J.; Jiménez-Barbero, J.; Avenoza, A.; Busto, J.; Bernardes, G.; Peregrina, J.; Hurtado-Guerrero, R.; Corzana, F., Deciphering the Non-Equivalence of Serine and Threonine O-Glycosylation Points: Implications for Molecular Recognition of the Tn Antigen by an anti-MUC1 Antibody. Angew Chem Int Ed Engl 2015, 54, 9830-9834.

4. Panchamoorthy, G.; Jin, C.; Raina, D.; Bharti, A.; Yamamoto, M.; Adeebge, D.; et al. Targeting the human MUC1-C oncoprotein with an antibody-drug conjugate. JCI Insight 2018, 3, e99880.

5. Loureiro, L.; Carrascal, M.; Barbas, A.; Ramalho, J.; Novo, C.; Delannoy, P.; Videira, P., Challenges in Antibody Development against Tn and Sialyl- Tn Antigens. Biomolecules 2015, 5, 1783-1809.

6. Karsten, U.; Serttas, N.; Paulsen, H.; Danielczyk, A.; Goletz, S., Binding patterns of DTR-specific antibodies reveal a glycosylation-conditioned tumor-specific epitope of the epithelial mucin (MUC1). Glycobiology 2004, 14, 681-692.

7. Fernández, E.; Navo, C.; Martínez-Sáez, N.; Gonçalves-Pereira, R.; Somovilla, V.; Avenoza, A.; et al., Tn Antigen Mimics Based on sp2-Iminosugars with Affinity for an anti-MUC1 Antibody. Org. Lett 2016, 18, 2796-2799.

8. Movahedin, M.; Brooks, T.; Supekar, N.; Gokanapudi, N.; Boons, G.; Brooks, C., Glycosylation of MUC1 influences the binding of a therapeutic antibody by altering the conformational equilibrium of the antigen. Glycobiology 2017, 27, 677-687.

9. Katayose, Y.; Kudo, T.; Suzuki, M.; Shinoda, M.; Saijyo, S.; Sakurai, N.; et al., MUC1-specific targeting immunotherapy with bispecific antibodies: Inhibition of xenografted human bile duct carcinoma growth. Cancer Res 1996, 56, 4205-4212.

10. Kodama, H.; Suzuki, M.; Katayose, Y.; Shinoda, M.; Sakurai, N.; Takemura, S.-I.; et al., Specific and effective targeting cancer immunotherapy with a combination of three bispecific antibodies. Immunol Lett 2002, 81, 99-106.

11. Wilkie, S.; Picco, G.; Foster, J.; Davies, D.; Julien, S.; Cooper, L.; Arif, S.; Mather, S.; Taylor-Papadimitriou, J.; Burchell, J.; Maher, J., Retargeting of human T cells to tumor-associated MUC1: the evolution of a chimeric antigen receptor. J Immunol 2008, 180, 4901-4909. 
12. You, F.; Jiang, L.; Zhang, B.; Lu, Q.; Zhou, Q.; Liao, X.; et al., Phase 1 clinical trial demonstrated that MUC1 positive metastatic seminal vesicle cancer can be effectively eradicated by modified Anti-MUC1 chimeric antigen receptor transduced T cells. Science China Life Sci 2016, 59, 386-397.

13. de Bono, J.; Rha, S.; Stephenson, J.; Schultes, B.; Monroe, P.; Eckhardt, G.; et al., Phase I trial of a murine antibody to MUC1 in patients with metastatic cancer: Evidence for the activation of humoral and cellular antitumor immunity. Ann Oncol 2004, 15, 1825-1833.

14. Mehla, K.; Tremayne, J.; Grunkemeyer, J.; O'Connell, K.; Steele, M.; Caffrey, T.; et al., Combination of mAb-AR20.5, anti-PD-L1 and PolyICLC inhibits tumor progression and prolongs survival of MUC1.Tg mice challenged with pancreatic tumors. Cancer Immunol Immunother 2018, 67, 445-457.

15. Al-Wasaby, S.; de Miguel, D.; Aporta, A.; Naval, J.; Conde, B.; Martínez-Lostao, L.; Anel, A., In vivo potential of recombinant granulysin against human tumors. OncoImmunol 2015, 4, e1036213.

16. Al-Wasaby, S.; Guerrero-Ochoa, P.; Ibáñez-Pérez, R.; Soler, R.; Conde, B.; Martínez-Lostao, L.; Anel, A., In vivo potential of recombinant granulysin against human melanoma. Cance Treat Res Commun 2021, $27,100355$.

17. Aporta, A.; Catalán, E.; Galán-Malo, P.; Ramírez-Labrada, A.; Pérez, M.; Azaceta, G.; Palomera, L.; Naval, J.; Marzo, I.; Pardo, J.; Anel, A., Granulysin induces apoptotic cell death and cleavage of the autophagy regulator Atg5 in human hematological tumors. Biochem Pharmacol 2014, 87, 410-423.

18. Gamen, S.; Hanson, D. A.; Kaspar, A.; Naval, J.; Krensky, A. M.; Anel, A., Granulysin-induced apoptosis. I. Involvement of at least two distinct pathways. J. Immunol. 1998, 161, 1758-1764.

19. Ibáñez-Pérez, R.; Guerrero-Ochoa, P.; Al-Wasaby, S.; Navarro, R.; Tapia-Galisteo, A.; De Miguel, D.; Gonzalo, O.; Conde, B.; Martínez-Lostao, L.; Hurtado-Guerrero, R.; Sanz, L.; Anel, A., Anti-tumoral potential of a human granulysinbased, CEA-targeted cytolytic immunotoxin. Oncolmmunol 2019, 8, 1641392.

20. Sanz, L.; Ibáñez-Pérez, R.; Guerrero-Ochoa, P.; Lacadena, J.; Anel, A., Antibody-Based Immunotoxins for Colorectal Cancer Therapy. Biomedicines 2021, 9, 1729.

21. Guerrero-Ochoa, P.; Aguilar-Machado, D.; Ibáñez-Pérez, R.; Macías-León, J.; Hurtado-Guerrero, R.; Raso, J.; Anel, A., Production of a Granulysin-Based, Tn-Targeted Cytolytic Immunotoxin Using Pulsed Electric Field Technology Int J Mol Sci 2020, 21, 6165.

22. Fujita, R.; Hamano, H.; Kameda, Y.; Arai, R.; Shimizu, T.; Ota, M.; et al., Breast cancer cells expressing cancer-associated sialyl-Tn antigen have less capacity to develop osteolytic lesions in a mouse model of skeletal colonization. Clin Exp Metastasis 2019, 36, 539-549.

23. Sipos, B.; Möser, S.; Kalthoff, H.; Török, V.; Löhr, M.; Klöppel, G., A comprehensive characterization of pancreatic ductal carcinoma cell lines: towards the establishment of an in vitro research platform. Virchows Arch 2003, 442, 444-452.

24. Brown, T.; Shuford, W.; Wang, W.; Nadler, S.; Bailey, T.; Marquardt, H.; Mittler, R., Characterization of a CD43/leukosialin-mediated pathway for inducing apoptosis in human T-lymphoblastoid cells. J Biol Chem 1996, 271, 27686-27695.

25. Posey, A.; Schwab, R.; Boesteanu, A.; Steentof, C.; Mandel, U.; Engels, B.; Stone, J.; Madsen, T.; Schreiber, K.; Haines, K.; et al., Engineered CAR T Cells Targeting the Cancer-Associated Tn-Glycoform of the Membrane Mucin MUC1 Control Adenocarcinoma. Immunity 2016, 44, 1444-1454.

26. Martinez-Lostao, L.; de Miguel D; Al-Wasaby, S.; Gallego-Lleyda, A.; Anel, A., Death ligands and granulysin: mechanisms of tumor cell death induction and therapeutic opportunities. Immunotherapy 2015, 7, 883-892. 
27. de Miguel, D.; Basáñez, G.; Sánchez, D.; Galán, P.; Marzo, I.; Larrad, L.; Naval, J.; Pardo, J.; Anel, A.; Martínez-Lostao, L., Thethering Apo2L/TRAIL to liposomes overcomes chemoresistance of human hematological tumor cells. Mol. Pharm. 2013, 10, 893-904.

28. Crespo, Â.; Mulik, S.; Dotiwala, F.; Ansara, J.; Sen Santara, S.; Ingersoll, K.; Ovies, C.; Junqueira, C.; Tilburgs, T.; Strominger, J.; Lieberman, J., Decidual NK Cells Transfer Granulysin to Selectively Kill Bacteria in Trophoblasts. Cell 2020, 182, 1125-1139.

29. Dotiwala, F.; Mulik, S.; Polidoro, R.; Ansara, J.; Burleigh, B.; Walch, M.; Gazzinelli, R.; Lieberman, J., Killer lymphocytes use granulysin, perforin and granzymes to kill intracellular parasites. Nature Med 2016, 22, 210-216.

30. Stenger, S.; Hanson, D. A.; Teitelbaum, R.; Dewan, P.; Niazi, K. R.; Froelich, C. J.; Ganz, T.; Thoma-Uszynski, S.; Melián, A.; Bogdan, C.; Porcelli, S. A.; Bloom, B. R.; Krensky, A. M.; Modlin, R. L., An antimicrobial activity of cytolytic T cells mediated by granulysin. Science 1998, 282, 121-125.

31. Kishi, A.; Takamori, Y.; Ogawa, K.; Takano, S.; Tomita, S.; Tanigawa, M.; Niman, M.; Kishida, T.; Fujita, S., Differential expression of granulysin and perforin by NK cells in cancer patients and correlation of impaired granulysin expression with progression of cancer. Cancer Immunol. Immunother. 2002, 50, 604-614.

32. Pagès, F.; Berger, A.; Camus, M.; Sanchez-Cabo, F.; Costes, A.; Molidor, R.; Mlecnik, B.; Kirilovsky, A.; Nilsson, M.; Damotte, D.; al., e., Effector Memory T Cells, Early Metastasis, and Survival in Colorectal Cancer. New Eng. J. Med. 2005, 353, 2654-2666.

33. Sparrow, E.; Bodman-Smith, M., Granulysin: The attractive side of a natural born killer. Immunol Lett 2020, 217, 126-132.

34. Tong, X.; Qu, X.; Wang, M., A Four-Gene-Based Prognostic Model Predicts Overall Survival in Patients With Cutaneous Melanoma. Front Oncol 2021, 11, 639874.

35. Huang, L. P.; Lyu, S. C.; Clayberger, C.; Krensky, A. M., Granulysin-Mediated Tumor Rejection in Transgenic Mice. J. Immunol. 2007, 178, 77-84.

36. Bacac, M.; Fauti, T.; Sam, J.; Colombetti, S.; Weinzierl, T.; Ouaret, D.; Bodmer, W.; Lehmann, S.; Hofer, T.; Hosse, R.; et al., A Novel Carcinoembryonic Antigen T-Cell Bispecific Antibody (CEA TCB) for the Treatment of Solid Tumors. Clin Cancer Res 2016, 22, 3286-3297.

37. Qu, C.; Li, Y.; Song, Y.; Rizvi, S.; Raja, C.; Zhang, D.; Samra, J.; Smith, R.; Perkins, A.; Apostolidis, C.; Allen, B., MUC1 expression in primary and metastatic pancreatic cancer cells for in vitro treatment by (213)Bi-C595 radioimmunoconjugate $\mathrm{Br} J$ Cancer 2004, 91, 2086-2093.

38. Mazal, D.; Lo-Man, R.; Bay, S.; Pritsch, O.; Dériaud, E.; Ganneau, C.; Medeiros, A.; Ubillos, L.; Obal, G.; Berois, N.; Bollati-Fogolin, M.; Leclerc, C.; Osinaga, E., Monoclonal antibodies toward different Tn-amino acid backbones display distinct recognition patterns on human cancer cells. Implications for effective immuno-targeting of cancer Cancer Immunol Immunother 2013, 62, 1107-1122.

39. Medeiros, A.; Berois, N.; Incerti, M.; Bay, S.; Franco Fraguas, L.; Osinaga, E., A Tn antigen binding lectin from Myrsine coriacea displays toxicity in human cancer cell lines J Nat Med 2013, 67, 247-254.

40. Anderson, D. H.; Sawaya, M. R.; Cascio, D.; Ernst, W.; Modlin, R. L.; Krensky, A. M.; Eisenberg, D., Granulysin crystal structure and a structure-derived lytic mechanism. J. Mol. Biol. 2003, 325, 355-365.

41. Barman, H.; Walch, M.; Latinovic-Golic, S.; Dumrese, C.; Dolder, M.; Groscurth, P.; Ziegler, U., Cholesterol in Negatively Charged Lipid Bilayers Modulates the Effect of the Antimicrobial Protein Granulysin. J. Membrane Biol. 2006, 212, 29-39. 
42. Anel, A.; Naval, J.; Desportes, P.; Gonzalez, B.; Uriel, J.; Piñeiro, A., Increased cytotoxicity of polyunsaturated fatty acids on human tumoral B and T-cell lines compared with normal lymphocytes. Leukemia 1992, 6, 680-688.

43. Anel, A.; Naval, J.; González, B.; Torres, J. M.; Mishal, Z.; Uriel, J.; Piñeiro, A., Fatty acid metabolism in human lymphocytes. I. Time-course changes in fatty acid composition and membrane fluidity during blastic transformation of peripheral blood lymphocytes. Biochim. Biophys. Acta 1990, 1044, 323-331.

44. Aporta, A., La granulisina como péptido anti-tumoral y el papel de la apoptosis en la inmunidad frente a M. Tuberculosis. Ph.D. Thesis. University of Zaragoza. Spain 2014.

45. Kaspar, A. A.; Okada, S.; Kumar, J.; Poulain, F. R.; Drouvalakis, K. A.; Kelekar, A.; Hanson, D. A.; Kluck, R. M.; Hitoshi, Y.; Johnson, D. E.; Froelich, C. J.; Thompson, C. B.; Newmeyer, D. D.; Anel, A.; Clayberger, C.; Krensky, A. M., A distinct pathway of cell-mediated apoptosis initiated by granulysin. J. Immunol. 2001, 167, 350-356.

46. Pardo, J.; Pérez-Galán, P.; Gamen, S.; Marzo, I.; Monleón, I.; Kaspar, A. A.; Susín, S. A.; Kroemer, G.; Krensky, A. M.; Naval, J.; Anel, A., A role of the mitochondrial apoptosis-inducing factor (AIF) in granulysin-induced apoptosis. J. Immunol. 2001, 167, 1222-1229.

47. Saini, R. V.; Wilson, C.; Finn, M. W.; Wang, T.; Krensky, A. M.; Clayberger, C., Granulysin delivered by cytotoxic cells damages endoplasmic reticulum and activates caspase-7 in target cells. J. Immunol. 2011, 186, 4497-3504.

48. Hlongwane, P.; Mungra, N.; Madheswaran, S.; Akinrinmade, O.; Chetty, S.; Barth, S., Human Granzyme B Based Targeted Cytolytic Fusion Proteins. Biomedicines 2018, 6, pii: E72.

49. Mazor, R.; Onda, M.; Pastan, I., Immunogenicity of therapeutic recombinant immunotoxins. Immunol Rev 2016, $270,152-164$.

50. Logue, S.; Elgendy, M.; Martin, S., Expression, purification and use of recombinant annexin V for the detection of apoptotic cells. Nat Protoc 2009, 4, 1383-1395. 